\title{
Social Efficiency
}




\title{
SOCIAL EFFICIENCY
}

\author{
A Concise \\ Introduction to \\ Welfare Economics
}

\author{
SECOND EDITION
}

Peter Bohm

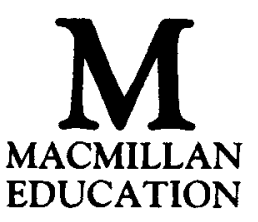


All rights reserved. No reproduction, copy or transmission of this publication may be made without written permission.

No paragraph of this publication may be reproduced, copied or transmitted save with written permission or in accordance with the provisions of the Copyright Act 1956 (as amended), or under the terms of any licence permitting limited copying issued by the Copyright Licensing Agency, 7 Ridgmount Street, London WC1E 7AE.

Any person who does any unauthorised act in relation to this publication may be liable to criminal prosecution and civil claims for damages.

First edition 1973

Reprinted (with corrections) 1976, 1977 (twice), 1978, 1979, 1984

Second edition 1987

Published by

MACMILLAN EDUCATION LTD

Houndmills, Basingstoke, Hampshire RG21 2XS

and London

Companies and representatives

throughout the world

Typeset by

TecSet Ltd, Wallington, Surrey

British Library Cataloguing in Publication Data

Bohm, Peter

Social efficiency: a concise introduction

to welfare economics. -2 nd ed.

1. Welfare economics

I. Title

$330.15^{\prime} 5$ HB99.3

ISBN 978-0-333-44135-0 ISBN 978-1-349-18786-7 (eBook)

DOI 10.1007/978-1-349-18786-7 


\section{Contents}

Preface ix

Introduction $\quad x i$

Social Efficiency and the Perfect Market Economy 1

1.1 Pareto Optimality in a Pure Barter Economy 2

1.2 A Production Economy (One Factor of Production) 8

1.3 Production with Many Factors and of Many Goods 11

1.4 A Market Economy 14

1.5 An Intertemporal Economy 19

1.6 Summary 23

Imperfections and the Need for Allocation Policy 24

2.1 External Effects 25

2.1.1 Definitions and examples 25

2.1.2 Optimum conditions and economic policy 30

2.1.3 Summary 41

2.2 Public Goods 41

2.2.1 Optimum conditions 41

2.2.2 Determination of demand for public goods 44

2.2.3 Transformation of public goods into marketable goods 45

2.2.4 Summary 46 
2.3 Decreasing Cost Industries (Economies of Scale) 46

2.3.1 The pricing problem 48

2.3.2 The investment criterion 49

2.3.3 Summary 51

2.4 Technical Imperfections - A Concluding

Comment 52

2.5 Market Disequilibrium 53

2.5.1 Welfare implications of a permanent excess demand 54

2.5.2 Motives for and alternatives to price regulation 57

2.5.3 Summary 58

2.6 Imperfect Competition 58

2.6.1 Allocative effects of monopoly behaviour 59

2.6.2 Policy measures 62

2.6.3 Long-term effects of 'antitrust policy' 64

2.6.4 Summary 65

2.7 Imperfect Information

2.7.1 Effects of imperfect information on consumer choice 66

2.7.2 The value of additional information 69

2.7.3 Socially efficient information activity 71

2.7.4 Summary 74

2.8 The 'Imperfect' Economy $\mathbf{7 4}$

2.8.1 Second-best policy 74

2.8.2 Allocation policy combined with other policies 76

2.8.3 Imperfect economic policy 78

3 Efficiency Aspects of Employment and Distribution 3 Policy 82

3.1 Allocative Effects of Tax Policy 82

3.1.1 Allocative effects of excise taxes 83

3.1.2 Allocative effects of income taxes 85

3.1.3 Are there neutral taxes? 89

3.1.4 Summary 90

3.2 Efficiency Aspects of Distribution Policy 91

3.2.1 Are negative taxes an efficient form of welfare policy? 92

3.2.2 Subsidised investments and efficiency in regional economic policy 98 
3.2.3 Efficient intertemporal distribution policy and the level of aggregate investment 102

3.2.4 Government aid and efficient assistance to poor countries 104

3.2.5 Summary 109

Cost-benefit Analysis of Public Investments and Policy Measures 112

4.1 The Quantification Problem 116

4.2 The Valuation Problem 117

4.2.1 Valuation of benefit items 118

4.2.2 Valuation of project costs 125

4.2.3 Many projects 127

4.2.4 Imperfect market prices 128

4.3 The Discounting Problem 132

4.3.1 Reasons for discounting future costs and benefits 132

4.3.2 The applicability of a market rate of interest 132

4.3.3 Market imperfections 133

4.3.4 Sensitivity analysis 136

4.4 The Constraints Problem 137

4.4.1 Distribution constraints 137

4.4.2 Budget constraints 138

4.5 The Uncertainty Problem 139

4.5.1 Uncertain project effects and accounting prices 140

4.5.2 Uncertain future discount rates and constraints 142

4.6 Intangible Effects 142

4.7 Applications of Cost-Benefit Analysis 144

4.7.1 Cost-benefit analysis applied to investment projects in depressed areas 144

4.7.2 A cost-benefit approach to analysing the effects of the introduction of commercial advertising on TV 150

4.8 Summary 153

Appendix 1 Necessary Conditions for Pareto Optimality 155

A.1.1 A derivation of the necessary conditions for Pareto optimality in a 'perfect' economy 155 
viii Contents

A1.2 Optimum conditions in the presence of imperfections

166

Appendix 2 The Consumer's Surplus

172

References

177

Index

181 


\section{Preface}

In this book, the main elements of welfare economics are presented in concise form. Welfare economics is that part of economics that, among other things, attempts to explain how to identify and arrive at socially efficient solutions to the resource allocation problems of the national (or local) economy. Expressed in another way, welfare economics tries to reduce the set of alternatives containing the 'best' solution for the economy by eliminating such solutions as can be shown to be inferior to other feasible solutions. The next step-choosing the 'best' or 'optimum' among the alternatives in this reduced set - is a question of subjective values and hence, not within the province of scientific analysis.

The book is primarily intended as a university text for the 'advanced beginner'. I believe that large parts of it, however, are accessible to other readers who have a serious interest in the efficiency problems of the economy. It should be observed that Chapters 2, 3 and 4 can each be read independently of the preceding parts of the book. It is difficult, however, to obtain a firm grasp of the contents of the book - and of Chapter 1 in particular - without prior elementary knowledge of microeconomic theory: the theory of the economic behaviour of firms and households. (See the list of literature at the end of the book for suggested preliminary reading.)

As indicated, the mode of presentation is brief and concise. Readers who prefer extensive explanations with many examples should therefore turn to other texts. In fact, the book is intended as an alternative to the extensive texts already available, an alternative meant to facilitate 
a cohesive overview of social efficiency problems in general and to expose the basic similarities among the many problems of resource allocation in the local or national economy.

In this revised edition of the book, the text has been expanded on a number of points. Major additions to the first edition can be found in Sections 2.1 (External Effects), 2.5 (Market Disequilibrium), 2.8 (The 'Imperfect' Economy), 3.2.2 (Regional Economic Policy), 4.2.4 (Imperfect Market Prices), 4.3 (The Discounting Problem) and in Appendices 1 and 2. The single most extensive addition is in section 2.8 which now includes a presentation of the public choice perspective on economic policy.

In the preparation of the book I have benefited from helpful comments by many colleagues. I am indebted to all of them and in particular to William Baumol, Ted Bergstrom, William Branson, Alf Carling, Margareta Johannesson, Edward Gramlich, E. J. Mishan and Lewis Taylor. Julie Sundquist has given valuable assistance in the preparation of the English version of the book. 


\section{Introduction}

The purpose of this book is to give the reader an insight into the meaning of social efficiency, efficient use of a nation's resources, optimal allocation of resources and similar expressions.

Social efficiency will hardly appear as a straightforward concept to the non-economist. In certain cases, however, social efficiency coincides with the more well-known concept of efficiency in a private enterprise, that is minimum production costs for a certain output, maximum profits and the like. And in these cases it may truly be said that 'what is good for General Motors is good for the country'. But in other cases the two concepts - social and private efficiency - do not coincide at all. This is liable to cause misunderstandings and even those who are expected to observe efficiency on a national level (such as politicians and government agencies) cannot avoid confusing the two concepts. In many countries this is particularly conspicuous in the field of public transport; bus and railway communications are shut down owing to losses at the 'firm' level even in instances where such measures can be shown to be a waste of resources from the point of view of society as a whole. The reason for this behaviour is often a belief that businesslike operations are always in the interest of the country or, at least, in the interest of the government. And this may be taken as an expression of the fact that the two efficiency aspects are generally believed to coincide more often than they actually do.

Social efficiency has also been misunderstood in another way and for a completely different reason. It is often alleged that efficiency in general is irrelevant for, or even incompatible with, values such as 'high 
cultural standards', 'healthy environment', etc. As we shall see, it is more often the other way round; acts aimed at achieving social efficiency can in fact be said to promote more of such values. Briefly speaking, this is so because social efficiency involves an attempt to take into account all individuals' evaluations of all consequences of economic acts - in other words, not only the direct or purely material consequences of such acts. Similarly, efficiency is sometimes believed to be incompatible with 'equity' or 'fairness' in the distribution of real income or welfare among people. In some respects there is such a conflict, requiring a so-called 'equity-efficiency tradeoff'. But, quite often it is the other way round; avoiding a waste of resources or increasing efficiency as much as possible tends to provide opportunities for improving the lot of those regarded as needy.

To many people economics seems difficult, even obscure. The main reason for this impression often turns out to be that the money or financial aspects of the matter tend to be confusing. The crucial economic aspects, however, are generally much easier to grasp if the "veil of money' is lifted and the problem is looked at in real terms. An example may clarify this proposition: say that a person has bought some pieces of wood for $f 10$ each to build something and it later turns out that he did not need them all. Although it is certainly correct to say that the boards did cost $£ 10$ each (and that an additional piece would cost that much) this does not normally say anything about the value of the remaining boards. The value is determined solely on the basis of the possible ways of using these boards that this person might now think of. Having considered all the alternatives - including that of reselling the boards - he may find that the best one, after all, is to burn them. In that event, if his child comes by looking for something to play with, giving the boards to the child would certainly not entail a real cost of f10 each (the purchase price), but only what they are considered to be worth as fuel. A considerable part of economics and especially the analysis of efficiency problems, is based on a so-called opportunity cost argument of this uncomplicated kind, that is on the value of the best alternative use of a given resource, be it an available commodity, a piece of machinery or an hour of work.

It is an unfortunate fact that the desire to spell out the details of a complex economic reality often makes it difficult to see the scope of the simple principle just mentioned. In an attempt to clarify this principle and to facilitate an overall view of the general problem of social efficiency, the presentation below is made relatively brief and free from examples and elaborate details. This approach is based on a 
belief that once a bird's eye perspective has been acquired, it will be easier - at least for the patient student - to scrutinise examples and understand real-world situations.

In line with this objective we start by giving a brief account of the main contents of this book.

1. It can be shown that a certain simple model of an economy - with, among other things, many buyers and sellers of every commodity can generate situations that are socially efficient in the sense that further changes which benefit all individuals are impossible. This property is not made irrelevant or unimportant by the mere fact that reality always deviates from the assumptions behind the model. As a point of departure it may be superior to the available alternatives, and as an approximation of parts of real-world economic problems it has the virtue of being simple. Moreover, the conclusions drawn from this model are certainly not unimportant from an historical and political point of view; they form the cornerstone of all propositions concerning the advantages of a market economy and of competition in the economic sphere.

2. Looking at the assumptions behind the model - the 'perfect market economy' model - we find that the lack of realism is due to the absence of phenomena such as monopoly and other forms of imperfect competition, increasing returns in production, the inability to organise markets for all commodities of interest to consumers, etc. It can be shown that a government interested in efficiency of the type mentioned in point 1 above can neutralise or eliminate such 'imperfections' and achieve efficient states for the economy by means of certain acts of economic policy ('allocation policy').

3. At the same time, the government may be interested in achieving one particular efficient state and thereby one particular 'income or welfare distribution' among the individuals participating in the economy. Moreover, the government may be dissatisfied with the way the economy behaves even if it tends towards the desired state. There are recurring 'accidents' in the form of temporary general unemployment and more enduring employment problems in certain regions or sectors. Economic policy measures are therefore taken also for the purpose of adjusting income distribution and combating tendencies towards general or local recession. As already indicated, conflict with the efficiency objective may arise in this pursuit. Moreover, alternative modes of such economic policy may differ in their ability to achieve distribution and stabilisation goals in an efficient 
way. Thus, there are reasons for observing efficiency aspects of economic policy in general.

4. Regardless of the actual choice of objectives for economic policy we can feel free to assume that the desired overall state of the economy will be one of maximum efficiency provided that certain stabilisation and distribution goals have been met. And maximum efficiency should be in the interest of the government (or the individual politician) regardless of the weight it (or he) attaches to these stabilisation and distribution goals - or other goals, for that matter. Given this uniform principle a general method can be established for decision-making or policy-making in individual cases of tax changes, new legislation, public investment projects, etc. - a so-called cost-benefit analysis.

These are the four points that will be dealt with in the four chapters of the book. We shall thus show (1) how and in what sense social efficiency can be attained in a 'perfect market economy', (2) how and in what sense real-world imperfections can be corrected by 'allocation policy', (3) what the relations are between efficiency and economic policy for stabilisation and distribution purposes and (4) what the costbenefit criterion for public investments and other specific government measures is. 